\title{
Oral medicine case book 75 : Mucoepidermoid carcinoma of the lower lip: review and a case report
}

SC Manenzhe ${ }^{1}$, SP Ngwenya ${ }^{2}$, SL Shangase ${ }^{3}$, GU Mohangi ${ }^{4}$

\begin{abstract}
Mucoepidermoid carcinoma (MEC) is the most common malignancy of salivary gland origin, comprising $30 \%$ of all these neoplasms. Major salivary glands are more commonly involved, with most MECs presenting in the parotid gland. The palate is the most commonly involved site in minor salivary glands. MEC of the lower lip is extremely rare with only a few cases reported in the literature. We report a case of a low grade MEC of the lower lip in a 49 year old female patient. She presented with a mass in the lower lip of six month's duration with a history of a recent rapid increase in size. Surgical resection was the treatment of choice and histopathological examination of the excised mass confirmed a diagnosis of low grade MEC. We present this case to highlight that although relatively rare, MEC should be included in the differential diagnoses of lower lip masses.
\end{abstract}

\section{INTRODUCTION}

MEC is a malignant epithelial salivary gland neoplasm characterised by proliferation of epidermoid, mucous and intermediate cells in varying proportions. ${ }^{1-3}$ The majority of tumours arising from the minor salivary glands are malignant. ${ }^{4}$ The MEC was first described by Stewart et al in 1945 as a mucoepidermoid tumour categorised into "favourable" (benign) and "unfavourable" (malignant) variants. ${ }^{5,6}$ It later, however, became apparent that all variants of the neoplasm are malignant and capable of loco-regional and distant metastasis, hence the adoption and endorsement of the term "MEC" by the Second 2005 WHO classification of salivary gland neoplasms., ${ }^{1,2}$ MEC is reported to represent $12-29 \%$ of all salivary gland malignancies ${ }^{2,6}$ and $2-16 \%$ of all salivary gland neoplasms. More than $50 \%$ of MECs present in major salivary glands with involvement of the parotid, submandibular and sublingual glands at $45 \%, 7 \%$ and $1 \%$ respectively. ${ }^{1}$ The palate is the most common site of involvement for minor

1. Shumani Manenzhe: $B C h D$, DipOdont (Oral Path). *

2. Sizakele Ngwenya: BSC, BDS, M.Dent (Oral Path). Department of Oral Pathology, School of Oral Health Sciences, University of the Witwatersrand, Johannesburg.

3. Sindisiwe Shangase: BDS, M.Dent (OMP). *

4. Govindrau Mohangi: BDS, DipOdont (Perio), DipOdont (Oral Med), MScOdont (Perio), MChD (OMP). *

* Department of Oral Medicine \& Periodontology, School of Oral Health Sciences, University of the Witwatersrand, Johannesburg

\section{Corresponding author}

Govindrau Mohangi:

Head: Clinical Unit, Department of Oral Medicine \& Periodontology School of Oral Health Sciences, Faculty of Health Science, University of the Witwatersrand. 7 York Road, Parktown, 2193, Johannesburg. Email: Govindrau.Mohangi@wits.ac.za

\section{ACRONYMS}

AFIP: Armed Forces Institute of Pathology

MEC: Mucoepidermoid carcinoma

salivary gland neoplasms with more than 50\% presenting at the junction between the hard and soft palate where minor salivary glands are most numerous., ${ }^{1,7-10}$ Other sites that may be involved include buccal mucosa, upper and lower lips, and the retromolar region. Minor salivary gland neoplasms account for $22 \%$ of all salivary gland malignancies and $12-30 \%$ of all salivary gland neoplasms. ${ }^{1,2,10}$ Although tumours of minor salivary glands are not as common as those involving major salivary glands, a biopsy is crucial when there is suspicion as more than $80 \%$ of minor salivary gland neoplasms are malignant in nature. ${ }^{3,9,11}$ Smoking, viral infections, working in rubber manufacturing and genetic susceptibility are some of the risk factors that have been reported in association with MEC.12 Prior exposure to radiation, however, is the only well established and most commonly associated risk factor for the development of MEC. ${ }^{13}$ Hiroshima and Nagasaki atomic bomb survivors and patients treated with radiation for various childhood malignancies, including lymphoma, sarcoma, retinoblastoma, and thyroid carcinoma, have an increased risk of developing MEC, with atomic bomb survivors reported to have an increased relative risk of 9,3 times. , $^{1,12,13}$ A recurring chromosomal translocation (t 11; 19) (q21; p13) resulting in the formation of the MECT1-MAML2 fusion oncogene has been identified in MECs. ${ }^{14-16}$ The translocation is demonstrated in $55-75 \%$ of low grade MECs and up to $46 \%$ of high grade MECs. ${ }^{15,17}$ MECT1-MAML2 fusion positive MECs are associated with improved survival. MEC gender predilection reported in literature has been cited as either non-existent or showing a slight female predisposition with a ratio of $3: 1{ }^{1,2,5,7,9}$ Although MEC can occur at any age, the peak incidence is between the third and sixth decades of life..$^{1,2,18}$ The MEC is the most common malignant salivary gland tumour in children and in adolescents under the age of $20 .{ }^{17}$ Palatal salivary gland tumours tend to present in young patients, 5-7 years younger than those involving other intraoral minor salivary glands, whereas MEC of the tongue tends to present in older patients. ${ }^{1-3}$ The MEC demonstrates diverse histomorphological features and biological behaviour, with prognosis correlated with histopathological grade, early detection and management.5,6,19 Treatment options for MEC include complete local excision for low grade MEC and surgical resection with or without radiation for high grade MECs. ${ }^{1-3}$ 


\section{CASE REPORT}

\section{A 49-year-old African female} patient presented with a six month history of a painless, slow growing swelling on the lower lip. The patient reported a 34-year history of snuff dipping on the lower labial sulcus, with a medical history that was non-contributory. Extraoral examination revealed palpable, mobile, non-tender bilateral

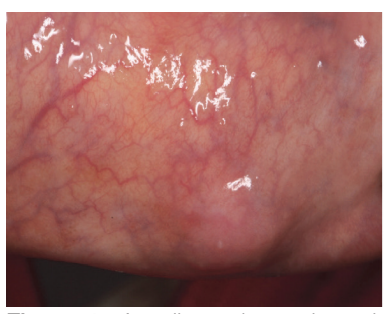

Figure 1: A solitary dome-shaped, smooth surfaced, non-ulcerated intramucosal swelling on the lower left labial mucosa. submandibular lymph nodes. On intra-oral examination, a solitary dome-shaped, smooth surfaced, non-ulcerated intramucosal swelling of normal colour was visible on the lower left labial mucosa (Figure 1).

The clinical differential diagnoses included mucocele, fibro-epithelial polyp, salivary gland neoplasm, lipoma and haemangioma. The lack of an associated history of trauma favoured the latter three options. The mass was surgically excised (Figure 2A). The specimen was multilobular; round to oval in shape with a yellowish cut surface, and measured $12 \times 8 \times 6 \mathrm{~mm}$ (Figure 2B).
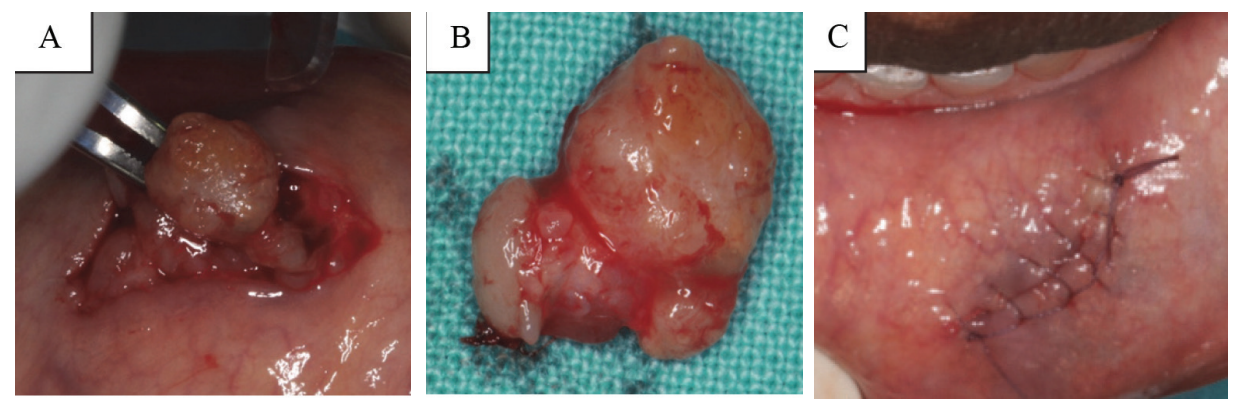

Figure 2: A. Biopsy of multi-lobular mass. B. Specimen sent for histological assessment. C. Post-operative surgical site.

Histopathological examination of the specimen showed features consistent with those of a mucoepidermoid carcinoma characterized by proliferation of neoplastic epidermoid, mucous and intermediate cells lying within a fibrous connective tissue stroma (Figure 3).

Cystic spaces lined by mucous cells and a few scattered basaloid and cuboidal intermediate cells were observed (Figure 4 A). On higher magnification of the tumour section, a focal area showing epidermoid, mucous and intermediate cells is observed (Figure 4B).
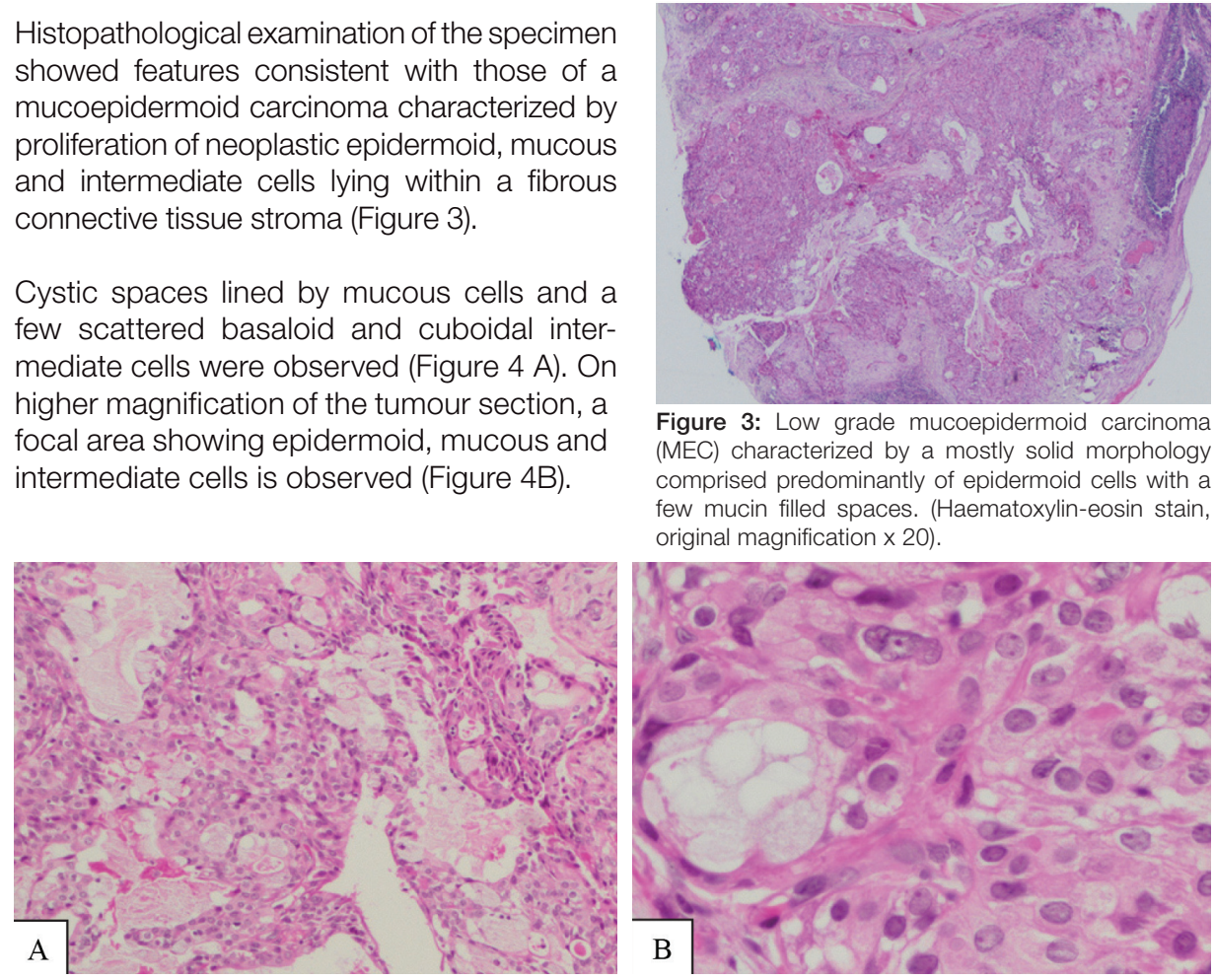

Figure 3: Low grade mucoepidermoid carcinoma (MEC) characterized by a mostly solid morphology comprised predominantly of epidermoid cells with a few mucin filled spaces. (Haematoxylin-eosin stain, original magnification $\times 20$ ).

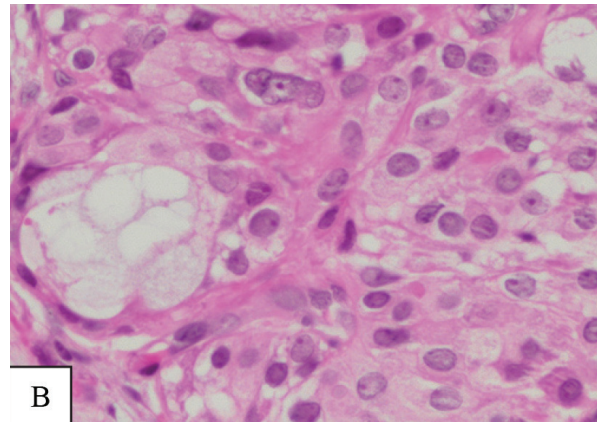

Figure 4: (A) Numerous cystic spaces lined by mucous secreting cells and a few scattered basaloid and cuboidal intermediate cells. (Haematoxylin-eosin stain, original magnification $x$ 100). (B) A focal area of the tumour showing epidermoid, mucous and intermediate cells. (Haematoxylin-eosin stain, original magnification x 400).
Histochemical examination demonstrated the presence of intra-cytoplasmic mucin in mucous cells and pools of muin as highlighted by diastase resistant Periodic Acid Schiff negative for S100 and SMA but positive for the P63 stain cellular anaplasia; thus giving it a total score of Two and a classification of a grade One/low grade MEC according to the Armed Forces Institute of Pathology grading system (AFIP). ${ }^{3,5}$ Positive tumour margins were identified and the wider excision margins. More than a year after the second

The correlation between the tumour size and the histological grade is in line with the observation made by Triantafillidou for a diameter less than $4 \mathrm{~cm}$, circumscription, lack of a and a predominantly cystic composition..$^{18}$ In our circumscription but had a predominantly solid composition. By demonstrating a cystic component of less than $20 \%$, our low grade MEC underscores the significant role played by factors other than the architectural growth pattern in the grading of MECs.

\section{GRADING CRITERIA}

The most popular grading systems for MECs are the Modified Healey, the AFIP and the Brandwein systems. ${ }^{2,3,7,18,20-23}$ All three grading systems classify MECs into three grades: low, intermediate and high grade. The Healey system places great emphasis on the morphological features of the tumour whereas the other two systems are point based and assess various histopathological parameters (Tables 1, 2 \& 3).

The Brandwein grading system is a modified AFIP grading system with three additional histopathological features (Tables $2 \& 3$ ). ${ }^{21,22}$ Currently no consensus exists with regard to which of the three systems is the best. The AFIP grading system is reproducible and demonstrates relatively good correlation between histological grade and clinical behaviour $^{1,2,8}$ but tends to downgrade MECs and to cluster intermediate and high grade tumours as reported by Brandwein et al. ${ }^{22} \mathrm{In}$ an attempt to correct this, Brandwein et al. modified the AFIP grading system 
Table 1: Mucoepidermoid Carcinoma: Modified Healey

Microscopic Grading System.

$\begin{array}{ll}\text { Grade } & \text { Characteristic features } \\ \text { Low } & \text { Differentiated mucin producing epidermoid cells, } \\ \text { often in a 1:1ratio; minimal to moderate intermedi- } \\ \text { ate cell population } \\ \text { Daughter cyst proliferation from large cysts } \\ \text { Minimal to absent pleomorphism, rare mitoses } \\ \text { Broad-front, often circumscribed invasion } \\ \text { Pools of extravasated mucin with stromal reaction } \\ \text { Intermediate } & \begin{array}{l}\text { No macrocysts, few microcysts, solid nests of cells } \\ \text { Large duct not conspicuous }\end{array} \\ & \text { Slight to moderate pleomorphism, few mitoses, } \\ \text { prominent nuclei and nucleoli } \\ \text { Invasive quality, usually well-defined and } \\ \text { uncircumscribed } \\ \text { Chronic inflammation at periphery, fibrosis } \\ \text { separates nests of cells and groups of nests } \\ \text { No macrocysts, predominantly solid but may be } \\ \text { nearly all glandular Cell constituents range from } \\ \text { poorly differentiated to recognizable epidermoid } \\ \text { and intermediate to ductal type adenocarcinoma } \\ \text { Considerable pleomorphism, easily found mitoses } \\ \text { Unquestionable soft tissue, perineural and } \\ \text { intravascular invasion } \\ \text { Chronic inflammation less prominent, desmoplasia } \\ \text { of stroma may outline invasive clusters }\end{array}$

Table 2: Mucoepidermoid Carcinoma: AFIP Microscopic Grading System.

\section{Histopathological Parameter}

Intracystic component <20\%

Neural Invasion

Necrosis

$\geq 4$ mitoses/ $10 \mathrm{HPF}^{*}$

Anaplasia

Tumour Grade:

Low

Intermediate

High

*HPF=high power fields

by increasing the weighting of perineural invasion when present from 2 to 3 and added three more parameters, namely, pattern of invasion, lymphovascular and bony invasion bringing the total number of histopathological parameters examined and scored to eight. ${ }^{20-22}$ Of these parameters necrosis, mitotic activity, perineural, lymphovascular and bony invasion are considered to be the main determinants of tumour grade. ${ }^{22}$ In both grading systems the individual scores are added and a grand total score is then used to classify MEC into low, intermediate, and high grades. ${ }^{21-23}$ However, Nance et al..$^{24}$ demonstrated that the Brandwein system is not without fault as it has a tendency to upgrade tumours, by clustering low grade and intermediate tumours. These differences have significant implications on treatment modalities and prognosis for MECs which are largely dependent on the histological grade of MECs. ${ }^{25}$ Regardless of these challenges, numerous studies have proven histological grading based on these systems to be the most significant independent prognostic factor for MECs. An exception to the rule is the MEC of the submandibular gland which is associated with increased risk for metastasis and poor prognosis irrespective of the histological grade. In addition to the site
Table 3: Mucoepidermoid Carcinoma: Brandwein Microscopic Grading System.

\begin{tabular}{l|c}
\multicolumn{1}{l}{ Histopathological Parameter } & Points \\
\hline Intracystic component $<25 \%$ & 2 \\
\hline Tumour front invades in small nests and islands & 2 \\
\hline Pronounced nuclear atypia & 2 \\
\hline Lymphovascular invasion & 3 \\
\hline Bony invasion & 3 \\
\hline 4 mitoses/10 HPF* & 3 \\
\hline Perineural invasion & 3 \\
\hline Necrosis & \multicolumn{2}{|c}{3} \\
\hline & Point score \\
\hline Low & $0-4$ \\
\hline Intermediate & $5-6$ \\
\hline High & 7 or more
\end{tabular}

*HPF=high power fields

of involvement, gender, age, clinical stage, disease-free margins and lymph node metastasis have proven to be of prognostic significance. ${ }^{26,27}$

\section{DISCUSSION}

The most common malignant tumours to arise from minor salivary gland tissue include mucoepidermoid carcinomas (21.8\%), adenocarcinomas (7.1\%), adenoid cystic carcinomas (6.3\%), and acinic cell carcinomas (1.6\%). In the past, prior to proper description, MECs, particularly the high grade variants have been misdiagnosed as squamous cell carcinoma or unspecified adenocarcinoma.,17 This is not surprising considering that high-grade tumours are predominantly solid, and show a great degree of cellular atypia similar to that seen in squamous cell carcinoma. ${ }^{21,23}$ The misdiagnoses and changes in the diagnostic and grading criteria of these salivary gland neoplasms also explain the conflicting data regarding the frequency of MECs reported in literature over the years, which on average was reported as $27 \%$ of all malignant salivary gland tumours before 1990, and 45\% thereafter. ${ }^{7}$ Although there are a few studies reporting on the MEC of the lower lip, 7,17 Neville et al. found in their study MEC to be the most common malignancy involving the lower lip, with 15 of 16 lower lip malignancies diagnosed as MEC. ${ }^{25}$ Most reported MECs are classified as low grade tumours, ${ }^{7}$ emphasizing the significant role of early disease detection in altering disease outcome and determining patient survival.

No causal effect relationship has been demonstrated in the literature between tobacco use, alcohol consumption and the development of salivary gland neoplasms. While the patient in the current case reported a 34-year history of snuff dipping on the lower labial sulcus adjacent to the site involved by the MEC, it is then unlikely that the development of the MEC on the lower labial mucosa is associated with the habit.

\section{CONCLUSION}

In conclusion, we present this case to highlight that, MEC, although relatively rare, should be included in the differential diagnoses of lower lip masses to guide the treatment approach, avoid recurrences and possible repeat surgery in order to achieve curative margins. Whilst 
it is unlikely that the MEC in this case was associated with the reported history of the use of smokeless tobacco (snuff dipping), given the 'coincidental' existence of the MEC on the site where the smokeless tobacco was habitually placed over the years, future studies should evaluate the possibility of this association.

\section{Declaration: No conflict of interest declared.}

\section{References}

1. Barnes EL, Eveson JW, Reichart P et al. World Health Organization Classification of Tumours. Pathology and Genetics of Head and Neck Tumours. Lyon, IARC Press, 2005: 219-20.

2. Eveson J, Nagao T. Diseases of the salivary glands. In: Barnes L, ed. Surgical Pathology of the Head and Neck, Vol 1, 3rd edition. NY: Informa Healthcare, 2008:546-52.

3. Auclair PL, Goode RK, Ellis GL. Mucoepidermoid carcinoma of intraoral salivary glands. Evaluation and application of grading criteria in 143 cases. Cancer 1992;69(8):2021-30.

4. Copelli C, Bianchi B, Ferrari S, Ferri A, Sesenna E. Malignant tumors of intraoral minor salivary glands. Oral Oncol 2008;44(7):658-63.

5. Ellis GL, Auclair PL, Armed Forces Institute of Pathology (U.S.), Universities Associated for Research and Education in Pathology. Tumors of the Salivary Glands. Armed Forces Institute of Pathology, under the auspices of Universities Associated for Research and Education in Pathology; 1996:468.

6. Stewart FW, Foote FW, Becker WF. Muco-epidermoid tumors of salivary glands. Ann Surg. 1945;122(5):820-44.

7. Pires FR, Pringle GA, de Almeida OP, Chen S-YY. Intra-oral minor salivary gland tumors: A clinicopathological study of 546 cases. Oral Oncol 2007;43(5):463-70.

8. Bruce M. Wenig. Atlas of Head and Neck Pathology 2nd Ed. Elsevier Health Sciences, 2008. 1139.

9. Abrahão AC, Santos Netto J de N, Pires FR, Santos TCRB dos, Cabral MG. Clinicopathological characteristics of tumours of the intraoral minor salivary glands in 170 Brazilian patients. Br J Oral Maxillofac Surg 2016;54(1):30-4.

10. Mishra S, Mishra YC. Minor salivary gland tumors in the Indian population: A series of cases over a ten year period. J oral Biol craniofacial Res 2014;4(3):174-80.

11. Namboodiripad PCA. A review: Immunological markers for malignant salivary gland tumors. J Oral Biol Craniofacial Res 2014;4(2):127-34.

12. Whatley WS, Thompson JW, Rao B. Salivary gland tumors in survivors of childhood cancer. Otolaryngol Head Neck Surg 2006;134(3):385-8.

13. Li FP. Second malignant tumors after cancer in childhood. Cancer 1977;40(4Suppl):1899-902.

14. McCord C, Weinreb I, Perez-Ordoñez B, Skalova A, Vanecek $\mathrm{T}$, Sima R, et al. Progress in salivary gland pathology: new entities and selected molecular features. Diagnostic Histopathol 2012;18(6):253-60.

15. Seethala RR, Dacic S, Cieply K, Kelly LM, Nikiforova MN. A reappraisal of the MECT1/MAML2 translocation in salivary mucoepidermoid carcinomas. Am J Surg Pathol 2010; 34(8):1106-21.

16. Bhaijee F, Pepper DJ, Pitman KT, Bell D. New developments in the molecular pathogenesis of head and neck tumors: A review of tumor-specific fusion oncogenes in mucoepidermoid carcinoma, adenoid cystic carcinoma, and NUT midline carcinoma. Ann Diagn Pathol 2011:69-77.

17. Okabe M, Miyabe S, Nagatsuka H, Terada A, Hanai N, Yokoi $\mathrm{M}$, et al. MECT1-MAML2 fusion transcript defines a favorable subset of mucoepidermoid carcinoma. Clin Cancer Res 2006;12(13):3902-7.

18. Triantafillidou K, Dimitrakopoulos J, Iordanidis F, Koufogiannis D. Mucoepidermoid carcinoma of minor salivary glands: A clinical study of 16 cases and review of the literature. Oral Dis. 2006;12(4):364-70.

19. Liu S, Ow A, Ruan M, Yang W, Zhang C, Wang L, et al. Prog- nostic factors in primary salivary gland mucoepidermoid carcinoma: an analysis of 376 cases in an Eastern Chinese population. Int J Oral Maxillofac Surg 2014;43(6):667-73.

20. Goode RK, Auclair PL, Ellis GL. Mucoepidermoid carcinoma of the major salivary glands: clinical and histopathologic analysis of 234 cases with evaluation of grading criteria. Cancer 1998;82(7):1217-24.

21. Batsakis JG, Luna MA. Histopathologic grading of salivary gland neoplasms: I. Mucoepidermoid carcinomas. Ann Otol Rhinol Laryngol 1990;99:835-8.

22. Brandwein MS, Ivanov K, Wallace DI, Hille JJ, Wang B, Fahmy A, et al. Mucoepidermoid carcinoma: a clinicopathologic study of 80 patients with special reference to histological grading. Am J Surg Pathol. 2001;25(7):835-45.

23. Seethala RR. An update on grading of salivary gland carcinomas. Head Neck Pathol. 2009;3(1):69-77.

24. Nance MA, Seethala RR, Wang Y, Chiosea SI, Myers EN, Johnson JT, et al. Treatment and survival outcomes based on histologic grading in patients with head and neck mucoepidermoid carcinoma. Cancer 2008;113(8):2082-9525.

25. Neville BW, Damm DD, Weir JC, Fantasia JE. Labial salivary gland tumors. Cancer 1988;61(10):2113-6.

26. Scully C, Bagan J V, Hopper C, Epstein JB. Oral cancer: Current and future diagnostic techniques. Am J Dent 2008;21:199-209.

27. Braakhuis BJM, Leemans CR, Visser O. Incidence and survival trends of head and neck squamous cell carcinoma in the Netherlands between 1989 and 2011. Oral Oncol 2014;50(7):670-5. 